\title{
Erratum to: The PELskin project-part III: a homogenized model of flows over and through dense poroelastic media
}

\author{
Giuseppe A. Zampogna $(\mathbb{D} \cdot$ Alessandro Bottaro
}

Published online: 5 April 2017

(C) Springer Science+Business Media Dordrecht 2017

\section{Erratum to: Meccanica \\ DOI 10.1007/s11012-016-0543-7}

Due to an unfortunate turn of events, "The PELskin project—part IV" article was published in Meccanica issue 52:7, 2017, whereas the plan was to publish "The PELskin project I-V" articles in one and the same Meccanica issue. With the publication of "The PELskin project" parts I, II, III and V in one and the same issue, we would like to bridge the gap to the PELskin project part IV by providing the reader the below info.

DOI 10.1007/s11012-016-0521-0

The PELskin project-part I: fluid-structure interaction for a row of flexible flaps: a reference study in oscillating channel flow
DOI 10.1007/s11012-016-0525-9

The PELskin project: part II-investigating the physical coupling between flexible filaments in an oscillating flow

DOI 10.1007/s11012-016-0543-7

The PELskin project—part III: a homogenized model of flows over and through dense poroelastic media

Meccanica (2017) 52:1503-1514

DOI 10.1007/s11012-016-0513-0

The PELskin project: part IV—control of bluff body wakes using hairy filaments

DOI 10.1007/s11012-016-0524-x

The PELskin project-part V: towards the control of the flow around aerofoils at high angle of attack using a self-activated deployable flap

The online version of the original article can be found under doi:10.1007/s11012-016-0543-7.

G. A. Zampogna $(\bowtie) \cdot$ A. Bottaro

DICCA, Università di Genova, Via Montallegro 1,

16145 Genoa, Italy

e-mail: giuseppe.zampogna@edu.unige.it

A. Bottaro

e-mail: alessandro.bottaro@unige.it 